\title{
Addendum: Tradeoffs between groundwater conservation and air pollution from agricultural fires in northwest India
}

Balwinder-Singh (D), Andrew J. McDonald (1), Amit K. Srivastava (D) and Bruno Gerard (1)

Addendum to: Nature Sustainability https://doi.org/10.1038/s41893-019-0304-4, published online 17 June 2019.

The following Acknowledgements section has been added:

'We recognize early investigative journalism that hypothesized associations between the Groundwater Acts and the air pollution crisis in northwest India (see S. Narain, Straw in the wind. Business Standard, 15 February 2015; https://go.nature.com/36lsmhR). We commend this and similar efforts (for example, A. Kumar, Monsanto's profits, not Diwali, creating smoke in Delhi. The Sunday Guardian, 3 November 2018; https://go.nature.com/3jks92f), and acknowledge the vital role of journalism for shaping and supporting innovative sustainability science.'

Published online: 7 October 2020

https://doi.org/10.1038/s41893-020-00632-z

(C) The Author(s), under exclusive licence to Springer Nature Limited 2020 